Article

\title{
Preventative Taping in Futsal: An Exploratory Analysis of Low-Dye Taping on Planter Force Distribution and Pain Sensitivity
}

\author{
Sebastian Klich ${ }^{1, * \mathbb{C}}$, Biye Wang ${ }^{2}{ }^{\mathbb{D}}$, Aiguo Chen ${ }^{2}$, Jun Yan ${ }^{2}$ and Adam Kawczyński ${ }^{1}$ \\ 1 Department of Paralympic Sport, University School of Physical Education in Wrocław, 51-617 Wrocław, \\ Poland; adam.kawczynski@awf.wroc.pl \\ 2 College of Physical Education, Yangzhou University, Yangzhou 225009, China; wangbiye@yzu.edu.cn (B.W.); \\ agchen@yzu.edu.cn (A.C.); yanjun@yzu.edu.cn (J.Y.) \\ * Correspondence: sebastian.klich@awf.wroc.pl
}

Received: 9 December 2019; Accepted: 7 January 2020; Published: 11 January 2020

check for updates

Featured Application: Low-dye taping plays a crucial role in the management and treatment of lower extremity musculoskeletal pain and injury. The clinical efficacy of low-dye taping can be used in treatment for foot pain, plantar fasciitis, excessive foot pronation, and arch support. This application could be used by physical therapists, coaches, athletic trainers, as well as players themselves.

\begin{abstract}
The purpose of the present study was to investigate the changes in plantar foot force distribution (i.e., the percentage of force and force distribution under the rearfoot and forefoot) and plantar pressure pain sensitivity maps in professional futsal players after long-term low-dye taping (LDT). The subjects $(n=25)$ were male futsal players (age $23.03 \pm 1.15$ years). During the experiment, a nonelastic tape was applied on the plantar foot surface according to the standards of LDP. The experimental protocol consisted of a 3-day cycle during which the plantar foot force distribution (FFD) and plantar pressure pain threshold (PPT) were measured: (1) before the tape was applied, (2) $24 \mathrm{~h}$ after application, and (3) $72 \mathrm{~h}$ after application. The results revealed a significant decrease in the force distribution under the rearfoot $(p \leq 0.001)$ and forefoot $(p \leq 0.001)$ on the right and left sides. Moreover, the results showed an increase in the plantar pressure pain threshold in all regions of the foot $(p \leq 0.001)$. The results of this study suggest that plantar fascial taping can be an effective method for normalizing the force distribution on the foot and reducing the plantar pain threshold. The findings provide useful information regarding the prevention of and physical therapy of lower extremity injuries in soccer and futsal.
\end{abstract}

Keywords: prevention; injury; overloads; team sport

\section{Introduction}

Futsal is an indoor version of soccer in which players need to perform multiple sprints, and it is characterized by high-intensity work phases [1]. Schmikli et al. [2] reported that the most percentage of medically treated injuries occurred in futsal among the top ten popular sports in the Netherlands. Moreover, Junge and Dvorak [1] showed the epidemiology of injuries in FIFA Futsal World Cups between 2000 and 2008. Their observations indicated that the ankles and the feet/toes were the most injured body parts with the highest absence rate (17.6\% of total injuries and $17.9 \%$ of absence). The injury risk factors are related to excessive loads causing excessive foot pronation, tibial stress syndrome, or plantar fasciitis [3].

Excessive forces during running and futsal/soccer training cause overuse injuries in the foot and ankle because the plantar foot force distribution (FFD) under the rearfoot and forefoot increases, 
and the plantar pressure pain threshold (PPT) decreases [3-5]. Podobarography and pressure algometry are reliable research tools that are commonly used in sport science and medicine to investigate foot function (assessed by FFD) and monitor pain sensation (assessed by PPT) [6,7]. The FFD may reflect the effect of functional or structural alterations in foot morphology and gait biomechanics and may be used to estimate injury probability. Furthermore, podobarography provides crucial information for training control, monitoring, and rehabilitation management $[8,9]$. Pressure algometry provides information about acute and chronic pain sensations [6]. Previous studies have focused on FFD to (1) prevent foot and ankle instability [3,10,11], (2) study specific movements [8,12], and (3) perform biomechanical analyses of shoes in futsal and soccer [13]. Prior studies have used PPT characteristics to assess pain sensation in different body locations (e.g., lower extremity muscles) [5,6,12]. It should be noted that only a limited number of studies have performed investigations with futsal or soccer players [8,9,13-15]. The results of both methods (i.e., podobarography and pressure algometry) can be analyzed together through topographical maps of the force distribution and pain sensitivity.

Recent studies suggest a need to conduct research based on biomechanical outcomes and clinical implications $[4,10]$. A possible solution to optimize FFD and increase PPT is to use low-dye taping (LDT). This taping technique may lead to increased foot motion [16], support of the medial longitudinal arch (MLA) [3], and changed loading patterns of the plantar surface [17]. The increased PPT may have resulted in the mechanical stimulation of cutaneous receptors [18], especially in the medial region of the plantar surface, maintaining optimal arch height and plantar fascia tension [3]. It has been shown that a lower MLA height causes pronation of the foot, while pronation provokes internal rotation of the tibia [18], greater tension in the tibialis anterior and posterior muscle, and peroneus longus muscle relief $[11,12]$. Our recent study investigated the effect of LDT on pressure pain sensitivity in posterior line muscles of the lower extremity (hamstrings and calf muscles) [6]. LDT is a type of plantar fascial taping that is mainly applied to reduce plantar fascia tension $[10,19]$ as well as to improve arch support $[4,20]$.

The clinical assessment of LDT is difficult because few studies have reported a clinical advantage [20,21]. To the best of our knowledge, there is a lack of evidence on the effectiveness of LDT regarding both FFD and PPT in soccer and/or futsal players [6,22]. Prior studies in the literature have investigated different types of taping techniques involving strips [4,6,13,16,21,23]. Newell et al. [4] and Vicenzino et al. [16] investigated the effect of LDT on plantar foot distribution in volunteers with navicular drop and asymptomatic subjects. Their observations have shown changes in plantar pressure distribution effectively, as well as greater support of MLA [4] and reduction of excessive foot pronation [16]. Franettovich et al. [13] observed a reduced level of activation of tibialis posterior, tibialis anterior, and peroneus longus after LDT intervention. In addition, Klich et al. [6] and Radford et al. [20] measured pain sensations after application. The main findings from these studies have confirmed that LDT increased PPT [6] and reduced pain sensations [20] in lower extremity muscles. Moreover, studies have used a short-term application period (from 10 to $20 \mathrm{~min}$ ) [4,13,16,21,23]. The current study design is based on an effective method of taping (LDT) and a long-term period of application (72 h) [6] because the clinical approach is very important in treatment strategies (e.g., time and frequency of application). A greater level of understanding of LDT techniques may be very useful in injury prevention of the lower extremity, especially for the foot and ankle. Thus, the purpose of the present study was to investigate the changes in plantar foot force distribution (i.e., the percentage of force and force distribution under the rearfoot and forefoot) and plantar pressure pain sensitivity in professional futsal players after long-term LDT. We hypothesized that a reduction in FFD and an increase in PPT over the feet would occur in response to arch support provided by LDT. 


\section{Materials and Methods}

\subsection{Study Design}

This study was a controlled laboratory study conducted in the Chinese-Polish Laboratory of Sport and Brain Science, that used a repeated measures design and an investigation period of $72 \mathrm{~h}$. Details of the study design have been previously reported in repeated measures studies evaluating the pressure pain sensitivity of the upper trapezius muscle [24], hamstring and calf muscles [6]. Since the FFD and PPT data could not be collected simultaneously due to practical issues in using both types of equipment, the order of testing was structured to minimize the length of time required for testing. The order of the measurements taken at baseline and 24 and $72 \mathrm{~h}$ after LDT was as follows: (1) FFD then (2) PPT.

\subsection{Participants}

Twenty-five male futsal players (age $23 \pm 1.2$ years, body height $179 \pm 3.6 \mathrm{~cm}$, body weight $76 \pm 6.7 \mathrm{~kg}$, BMI $23 \pm 2.8 \mathrm{~kg} / \mathrm{m}^{2}$ ) participated in the study. The players were members of a college futsal club and 1st Division Futsal League.

Two weeks prior to the main experiment, an initial measure trial was conducted to recruit futsal players into the study group. All participants met the inclusion criteria of having improper plantar distribution (a percentage of force distribution under the forefoot of $\leq 55 \%$ ). Additionally, to select a more consistent group we assumed the following criteria: $\geq 10$ years of training experience in futsal, had trained on the same surface and in the same futsal shoes (in the last 6 months) and had agreed to pause training $(72 \mathrm{~h})$ for the duration of tape application. Participants were excluded if they reported lower extremity/foot/toe trauma and/or operation (in the last 6 months) or reported not being able to undergo the strip tape application. Nobody was excluded from the research.

The study was explained to the participants, and they signed an informed consent form approved by the Senate Research Ethics Committee (project identification code: 26/2016; date of approval: 13 October 2016). All procedures were conducted in accordance with the Declaration of Helsinki.

\subsection{Experimental Procedures}

The experimental procedure was based on the LDT technique. A nonelastic cotton tape (width: $4 \mathrm{~cm}$ ) was applied on the plantar surfaces of both feet. The subject was placed prone, with his shoes removed, $90^{\circ}$ of flexion in the knee, and the foot in a neutral position. The investigator degreased and subsequently sprayed the plantar surface and both the lateral and medial edges of the foot with an adhesive. LDT application was performed in 4 stages: (1) base support at the height of the 1st to the 5 th metatarsal head; (2) base support on the lateral and medial edges (from the 5th to the 1st metatarsal head); (3) overlapping towards the calcaneus (from the lateral to the medial edge), and (4) reapplication on the lateral and medial edges (stage no 2) and at the height of the 1st to the 5th metatarsal head (stage no 1) (Figure 1) [6].

The experimental procedures included three measurements (within $72 \mathrm{~h}$ ) of FFD and PPT in the following order: (1) baseline (without LDT), (2) $24 \mathrm{~h}$ after LDT application (with LDT) and (3) $72 \mathrm{~h}$ after LDT application (without LDT) [6]. The LDT was applied for $72 \mathrm{~h}$ because of the greater effects that become apparent 24 to $72 \mathrm{~h}$ after application [16,25].

The first outcome was FFD, for which four parameters were investigated, i.e., the percentage of force distribution under the rearfoot $(\% \mathrm{FRF})$, the percentage of force distribution under the forefoot (\% FFF), force distribution under the 2nd and 3rd metatarsal heads (F2,3), and force distribution under the rearfoot (FRF) using an optical podobarograph, Zebris FDM-S (Medical GmbH, Germany). This platform (length $\times$ width: $320 \times 470 \mathrm{~mm}$ ) was equipped with 1504 sensors. FootPrint software was used to record and process data from the podobarograph platform. Prior to the test, the podobarograph was calibrated, and the participant was instructed about this trial. Each subject stood barefoot in a 
two-legged stance on the platform for $90 \mathrm{~s}$ with his eyes open. The test was performed three times, and the results were averaged [26].

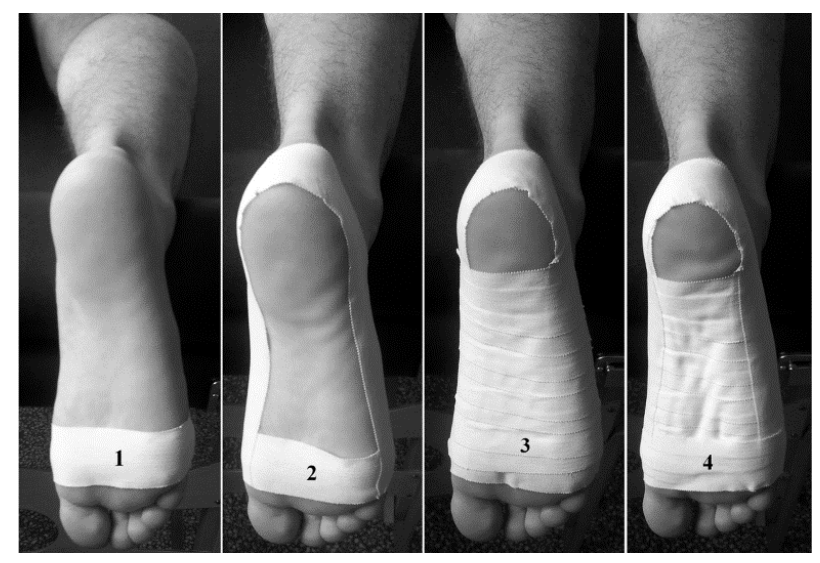

Figure 1. Low-dye taping technique.

The second outcome was PPT, which was measured at 7 reference points on the plantar surface using a pressure algometer (Somedic Production AB, Sweden). The device was equipped with a probe (area: $10 \mathrm{~mm}^{2}$ ), and the tip was covered with a $2 \mathrm{~mm}$ rubber. The compression on the reference points was standardized at $30 \mathrm{kPa} / \mathrm{s}$. The PPTs were characterized by the pressure, which caused pain sensations $[6,15]$. Each point was measured three times and then averaged. The measurements were performed on the plantar surfaces of both feet at the following locations: tuberosity of the calcaneus (1), medial side of the foot (2), midfoot (3), lateral board of the foot (4), 1st metatarsal head (I MTH) (5), 2nd and 3rd metatarsal space (II-III MTH), (6) and 5th metatarsal head (V MTH) (7) (Figure 2) [19].

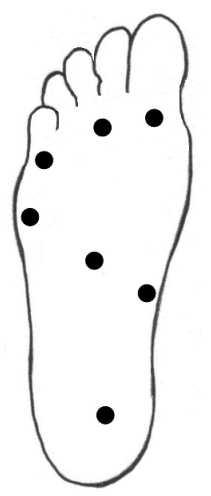

Figure 2. Plantar pressure pain reference points.

\subsection{Data Analysis}

The $G^{*}$ Power software (version 3.1.9.2; Kiel University, Kiel, Germany) was used to estimate the required sample size, the expected effect size was set at (Cohen's f) 0.65 , the $\alpha$ level was set at 0.05 , and the power $(1-\beta)$ was set at 0.9 . The procedure included a minimum number of 22 participants, but 25 were recruited to account for potential dropouts [27]. The relative and absolute reliability values of the FFD and PPT were computed using the intraclass correlation coefficient (ICC), standard error of measurement (SEM), and minimum detectable change (MDC) $[28,29]$. The relative reliability was evaluated by calculating a 2-way mixed $\mathrm{ICC}_{3,2}$ (for absolute agreement). Statistical analysis was performed using PAWS Statistic SPSS 18 software. Two-way repeated-measures analysis of variance (ANOVA) with post hoc Bonferroni corrections was performed on the FFD and PPT data. The region of the foot (rearfoot: \%FRF [\%], FRF [N] and forefoot (\%FFF [\%], FFF [N]) were included as independent factors in two-way, repeated-measures ANOVA for the FFD and FFD changes from 
baseline. Additionally, foot maps (location: $1-7$ ) were included as independent factors in two-way, repeated-measures ANOVA for the PPT and PPT changes from baseline. In all tests, $p \leq 0.05$ was considered significant.

\section{Results}

The intrarater test-retest reliability results were ICC(3.2) $=0.92, \mathrm{MDC} 90=0.34 \mathrm{~mm}$, and SEM $=0.13$ for the PFFD and $\operatorname{ICC}(3.2)=0.98, \operatorname{MDC}=0.04$, and SEM $=0.05$ for the PPPT [7]. The intrarater test-retest reliability results were $\operatorname{ICC}(3.2)=0.92, \mathrm{MDC} 90=0.34 \mathrm{~mm}$, and SEM $=0.13$ for the PFFD and $\operatorname{ICC}(3.2)=0.98, \mathrm{MDC}=0.04$, and SEM $=0.05$ for the PPT.

\subsection{Foot Force Distribution (FFD)}

As shown in Table 1, the average \%FRF increased significantly in the right foot $72 \mathrm{~h}$ after LDT application $\left(\mathrm{F}(36,48)=59.9, p \leq 0.001, \eta \mathrm{p}^{2}=0.84\right)$, while the average FRF [N] decreased significantly in the right foot $72 \mathrm{~h}$ after tape application $\left(\mathrm{F}(6,10)=42.6, p \leq 0.001, \eta \mathrm{p}^{2}=0.77\right)$. A significant decrease was observed in the average \%FFF $\left(\mathrm{F}(53,68)=64.5, p \leq 0.001, \eta p^{2}=0.85\right)$ and $\mathrm{F} 2,3(\mathrm{~F}(8,13)=130.7$, $\left.p \leq 0.001,175 \eta p^{2}=0.92\right)$ in the right foot $72 \mathrm{~h}$ after LDT application.

Table 1. Mean Values $( \pm \mathrm{SD})$ of the Plantar Foot Force Distribution Parameters in Futsal Players during $72 \mathrm{~h}$ Period of Plantar Fascial Taping.

\begin{tabular}{|c|c|c|c|c|c|c|}
\hline \multirow[t]{2}{*}{ Variable } & \multicolumn{3}{|c|}{ Right Foot } & \multicolumn{3}{|c|}{ Left Foot } \\
\hline & Baseline & $24 \mathrm{~h}$ & $72 \mathrm{~h}$ & Baseline & $24 \mathrm{~h}$ & $72 \mathrm{~h}$ \\
\hline$\%$ FRF [\%N] & $38.20 \pm 5.31^{a}$ & $41.64 \pm 4.6^{\mathrm{a}, \mathrm{b}}$ & $45.96 \pm 2.28^{b}$ & $39.04 \pm 6.21^{a}$ & $43.12 \pm 8.17^{a}$ & $45.80 \pm 3.75$ \\
\hline$\%$ FFF [\%N] & $61.80 \pm 5.18^{a}$ & $58.36 \pm 4.26^{\mathrm{a}, \mathrm{b}}$ & $54.04 \pm 2.28^{b}$ & $61.72 \pm 6.37^{a}$ & $57.04 \pm 8.40^{\mathrm{a}}$ & $54.52 \pm 3.00$ \\
\hline FRF [N] & $9.56 \pm 1.36^{\mathrm{a}}$ & $8.80 \pm 0.91^{\mathrm{a}, \mathrm{b}}$ & $7.06 \pm 0.71^{b}$ & $8.04 \pm 1.14^{\mathrm{a}}$ & $6.64 \pm 1.52^{\mathrm{a}}$ & $7.40 \pm 0.86$ \\
\hline $\mathrm{F} 2,3[\mathrm{~N}]$ & $12.84 \pm 1.80^{\mathrm{a}}$ & $11.36 \pm 1.55^{a, b}$ & $9.40 \pm 1.15^{b}$ & $12.52 \pm 1.23^{a}$ & $10.60 \pm 2.29^{a, b}$ & $9.12 \pm 1.13^{b}$ \\
\hline
\end{tabular}

Significant differences between variables at $p \leq 0.05$; ${ }^{\text {a }}$ baseline vs. $24 \mathrm{~h}$ and ${ }^{\mathrm{b}} 24 \mathrm{~h}$ vs. $72 \mathrm{~h}$.

\subsection{Pressure Pain Threshold (PPT)}

The average PPTs [kPa] increased significantly $72 \mathrm{~h}$ after LDT application $(\mathrm{F}(649,1620)=660.1$, $\left.p \leq 0.001, \eta_{\mathrm{p}}^{2}=0.96\right)$. The largest significant increase in PPT $24 \mathrm{~h}$ after LDT application was observed under the 2nd and 3rd metatarsal space $\left(\mathrm{F}(845,1422)=394.6, p \leq 0.001, \eta_{\mathrm{p}}{ }^{2}=0.99\right)$, midfoot $\left(\mathrm{F}(649,1234)=613.8 ; p \leq 0.001, \eta_{\mathrm{p}}{ }^{2}=0.97\right)$ and rearfoot $\left(\mathrm{F}(937,1620)=466.4, p \leq .0 .001, \eta_{\mathrm{p}}{ }^{2}=0.98\right)$.

The largest significant increase in PPT in $72 \mathrm{~h}$ after LDT application was reported under the medial board of the foot $\left(\mathrm{F}(653,1242)=656.42 ; p \leq 0.001, \eta_{\mathrm{p}}{ }^{2}=0.98\right)$, 5th metatarsal head $(\mathrm{F}(920,1444)=633.1$, $\left.p \leq 0.001, \eta_{\mathrm{p}}^{2}=0.98\right)$ and rearfoot $\left(\mathrm{F}(1250,1582)=466.0 ; p \leq 0.001, \eta_{\mathrm{p}}{ }^{2}=0.91\right)$ (Figure 3$)$.

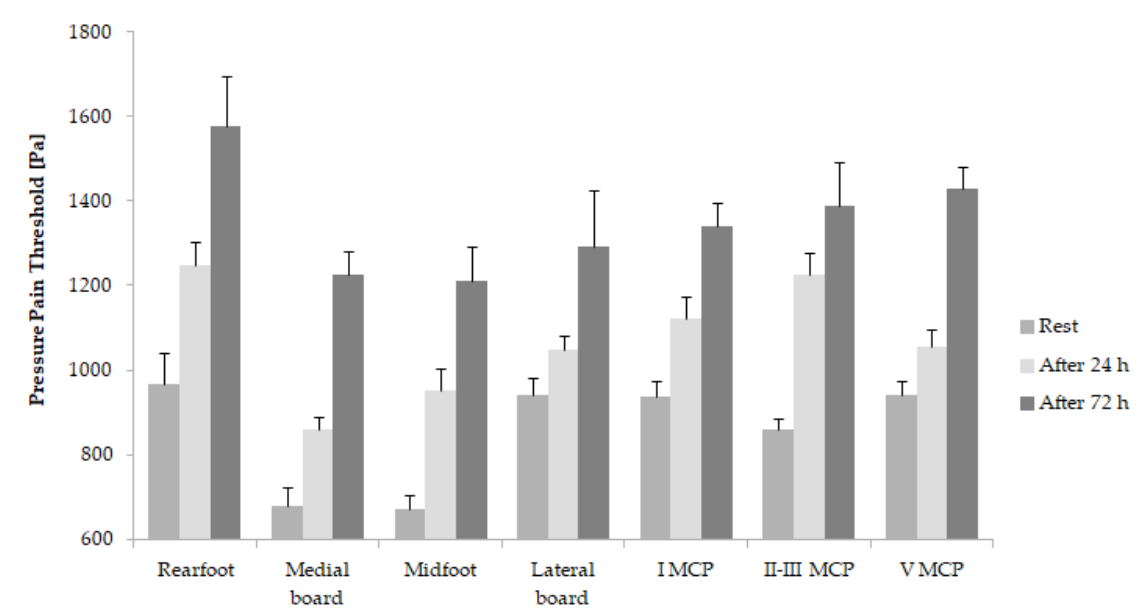

Figure 3. Plantar pressure pain threshold during $72 \mathrm{~h}$ period of plantar fascial taping in futsal players. 


\section{Discussion}

The present study has shown that the use of LDT resulted in the optimization of the force distribution and an increase in the pressure pain threshold under the feet after $72 \mathrm{~h}$ of tape application. The study has reported alterations in plantar soft tissue loads and pain sensitivity after low-dye taping intervention. The novelty of this study is based on the combination of podobarography and pressure algometry measurements as a comprehensive assessment of foot patterns. Our analysis compared plantar FFDs and PPTs in futsal players in reference to data taken in similar baseline (pre-measurement) conditions.

The taping technique methodology and study design applied in this study were different compared to previous studies. It should be noted that the aim was consistent with that from prior research. It has been shown that LDT is an effective taping technique for decreasing FFD in supported regions of the feet $[11,12,16,23,30]$. Our results indicated significant changes in the percentage of force distribution in the rearfoot and forefoot after 24 and $72 \mathrm{~h}$ and a decrease in peak force distribution under these foot regions. Lange et al. [12] observed a decrease in plantar pressure or peak force distribution in the medial and lateral rearfoot and forefoot (5 minutes after LDT application). Moreover, those changes have been observed only in LDT technique. Newell et al. [4], Vicenzino et al. [16], Chae et al. [31], and O'Sullivan et al. [32] have also confirmed an immediate effect of LDT. Additionally, all referenced papers provide an increase of plantar pressure or peak force distribution in the midfoot.

LDT may change rearfoot loading by reducing excessive pronation in the foot or greater stimulation of mechanoreceptors on the plantar surface [12]. According to Franettovich [13], a decrease in the rearfoot and forefoot pressure distribution may be caused by mechanical stimulation of cutaneous receptors on the plantar surface. Thus, the reduction of force distribution under the rearfoot might be related to the transfer of weight to the midfoot [12]. Those alterations in force distribution might be related to the reduction of pronation in subtalar and midtarsal joint, as well as, greater activity of tibialis posterior muscle [13,17,33]. Furthermore, Russo and Chipchase [34] observed a significantly greater pressure distribution under the rearfoot and lower pressure distribution under forefoot after LDT. In their opinion, greater pressure distribution under the midfoot might affect the reduction of pressure distribution under the rearfoot. Probably, those changes transferred to the rearfoot and reduced eversion at the calcaneus. According to Lange et al. [12], those observations found by Russo and Chipchase [34] could have been a result of experimental errors, i.e., the platform was not flush with the floor. Lack of significant changes in the FFD under other regions on the plantar surface might have been caused by the method of recruiting participants (e.g., healthy patients and athlete patients), alterations in biomechanical patterns, and reductions in tape adhesion [12,31].

Previous studies have reported that increased FFDs in the forefoot and rearfoot may lead to a loss of the MLA $[8,9,23]$. Vicenzino et al. [16] used a different technique of foot taping; their application was focused on MLA support. With this technique, the authors noticed a decrease in the force distributed in the medial region of the foot. In our study, we found an optimization in the percentage of force distributed between the rearfoot and forefoot, while a simultaneous increase in the \%FRF and a decrease in the FRF may indicate greater force distribution in the midfoot $[12,34,35]$. Decrease in the FRF and F2,3 may have been resulted in an increase in the PPTs under the rearfoot and forefoot. Previous data have shown typical plantar distribution patterns for running in soccer $[9,10]$. These observations may confirm our observations, as they indicate high FFDs under the forefoot, especially the central region of the foot (2nd and 3rd metatarsal head). Wong et al. [9] and Eils et al. [10] demonstrated that soccer-related movements, i.e., sideward cutting, $45^{\circ}$ cutting, jump, sprint, and kick may influence plantar distribution. In all those movements, a great pressure under the rearfoot and forefoot was observed. Additionally, Eils et al. [10] reported that the forefoot has the highest pressure distribution in soccer players during sprints.

The present study showed that the PPT increased in every investigated area of the plantar surface, which indicates a higher pain tolerance of the soft tissues in the plantar region of the foot. The highest increase in PPT (after $72 \mathrm{~h}$ ) was found under the rearfoot (an average of $40 \%$ ), medial board of the foot 
and midfoot (an average of $45 \%$ ), and forefoot (an average of 38\%). In our opinion, these changes in pain sensations can be related to excessive loads being favorably absorbed because of the application of tape. The results show that using LDT is beneficial for reducing excessive loads on the plantar tissues. Our data show that there are higher PPTs (baseline) in the rearfoot, lateral board, and 1st and 2nd-3rd metatarsal bones, which is in line with the findings shown in a recent study. Our results are similar to those reported by Madeleine et al. [19], i.e., the highest PPT was observed in the rearfoot. This finding may suggest lower loads in the rearfoot and less sensitivity to pressure. The significant increase in the PPTs after LDT may be associated with reduced tension on the plantar fascia. LDT application supports the MLA mainly by stimulation of the plantar fascia and proprioceptors. Thus, the plantar fascia is extending its length. Furthermore, the increase in the PPTs may also be related to increased soft tissue thickness $[19,25]$. Another study demonstrated an anti-pain effect of LDT by analysis of the Visual Analogue Scale (VAS) scores. A systematic review reported a significant decrease in pain sensation after an LDT intervention as a result of lower soft tissue sensitivity [36]. In addition, Domínguez-Martín et al. [37] observed higher PPT values for other muscles beyond the foot structures, such as the tibialis anterior, medial gastrocnemius, and erector spinae. Our previous study has shown that LDT application significantly increases the PPT in the hamstrings and calf muscles [6]. The main finding of our present results may suggest that a reduction in the peak force distribution under the rearfoot and forefoot, as well as that an increase in the PPT reduces pain sensitivity in posterior muscles of the lower extremity.

In the present study, the efficiency of LDT on FFD and PPT was related to a long-term $(72 \mathrm{~h})$ reduction in pain. Prior studies have reported only a short-term effect of LDT [12,13,21,30]. According to O'Sullivan et al. [32], how long and how often LDT must be applied and/or reapplied should be clarified. De Hoyo et al. [25] suggest that long-term effects are apparent 24-72 h after application. Slupik et al. [38] reported that an external stimulus through an elastic tape has a long-term effect ( 24 and $72 \mathrm{~h}$ ) on muscle activity in the lower extremity. However, Yoho et al. [33] have shown that $48 \mathrm{~h}$ taping techniques involving strips lead to a loss of MLA support. This finding was supported by the study of Slupik et al. [38], in which the effect was maintained for $48 \mathrm{~h}$.

Plantar fascial taping plays a crucial role in the management of plantar fascia injuries and improper mechanics of the ankle $[4,12]$ and reduces high pain sensitivity in the lower extremity muscles [6]. The clinical efficacy of LDT can be useful for the treatment of foot pain and arch support in futsal and soccer players. It is also important for maintain sustainable force distributions under the feet. Moreover, the practical application of those research findings may indicate useful information regarding the prevention of and physical therapy of lower extremity injuries in team sports. This method can be used by physical therapists, coaches, athletic trainers, and players themselves.

There are some limitations to the present study. First, a control group (non-taped subjects) should be recruited for this study to enhance the validity of the results. Alternatively, the results of our study would be more generalizable if the study included players with standard plantar force distributions. The second limitation is that we measured plantar force distributions only under the rearfoot and forefoot. Furthermore, the examination of the plantar force distribution was performed in static conditions because we were not able to study dynamic conditions. Third, the simultaneous collection of FFD and PPT data can reduce the accuracy of the results, especially the podobarograph results. The pressure algometer may cause internal bruising on the plantar surface.

\section{Conclusions}

This study has shown that LDT is, biomechanically and clinically, an effective taping technique for inducing appropriate distribution patterns in the rearfoot and forefoot. Our study showed that fascia taping optimized the force distribution under the plantar surface and reduced the pain sensitivity of the foot. These findings may indicate an adaptation to an external stimulus that results in the release of plantar soft tissues and stimulation of proprioception. These results provide evidence of the efficacy of LDT application after $72 \mathrm{~h}$. Therefore, by supporting the medial foot arch, the taping technique 
may be an effective method of preventing injury. More research is needed, however, to understand the mechanisms of this type of tape application in dynamic conditions and other taping techniques involving strips in soccer and futsal players.

Author Contributions: Conceptualization, S.K., and A.K.; methodology, S.K., and A.K.; formal analysis, B.W., A.C. and J.Y.; investigation, S.K., and A.K.; writing-original draft preparation, S.K.; writing-review and editing, A.C., J.Y. and A.K.; project administration, S.K., and B.W. All authors have read and agreed to the published version of the manuscript.

Funding: This research received no external funding.

Acknowledgments: We are grateful to the University authorities to join into Chinese-Polish Laboratory of Sport and Brain Science.

Conflicts of Interest: The authors declare no conflict of interest.

\section{References}

1. Junge, A.; Dvorak, J. Injury risk of playing football in Futsal World Cups. Br. J. Sports Med. 2010, 44, 1089-1092. [CrossRef] [PubMed]

2. Schmikli, S.L.; Backx, F.J.; Kemler, H.J.; van Mechelen, W. National survey on sports injuries in the Netherlands: Target populations for sports injury prevention programs. Clin. J. Sport Med. 2009, 19, 101-106. [CrossRef] [PubMed]

3. Cain, L.E.; Nicholson, L.L.; Adams, R.D.; Burns, J. Foot morphology and foot/ankle injury in indoor football. J. Sci. Med. Sport 2007, 10, 311-319. [CrossRef] [PubMed]

4. Newell, T.; Simon, J.; Docherty, C.L. Arch-Taping Techniques for Altering Navicular Height and Plantar Pressures During Activity. J. Athl. Train. 2015, 50, 825-832. [CrossRef]

5. Neal, B.S.; Griffiths, I.B.; Dowling, G.J.; Murley, G.S.; Munteanu, S.E.; Franettovich Smith, M.M.; Collins, N.J.; Barton, C.J. Foot posture as a risk factor for lower limb overuse injury: A systematic review and meta-analysis. J. Foot Ankle Res. 2014, 7, 55. [CrossRef]

6. Klich, S.; Goliński, D.; Stawarz, M.; Wolański, P. Influence of Plantar Fascial Taping on Pressure Pain Sensitivity Changes in Lower Extremity Posterior Line Muscles in Futsal Players. Cent. Eur. J. Sport Sci. Med. 2015, 3, $15-23$.

7. Klich, S.; Krymski, I.; Michalik, K.; Kawczynski, A. Effect of short-term cold-water immersion on muscle pain sensitivity in elite track cyclists. Phys. Ther. Sport 2018, 32, 42-47. [CrossRef]

8. Gurney, J.K.; Kersting, U.G.; Rosenbaum, D. Between-day reliability of repeated plantar pressure distribution measurements in a normal population. Gait Posture 2008, 27, 706-709. [CrossRef]

9. Wong, P.L.; Chamari, K.; Mao, D.W.; Wisloff, U.; Hong, Y. Higher plantar pressure on the medial side in four soccer-related movements. Br. J. Sports Med. 2007, 41, 93-100. [CrossRef]

10. Eils, E.; Streyl, M.; Linnenbecker, S.; Thorwesten, L.; Volker, K.; Rosenbaum, D. Characteristic plantar pressure distribution patterns during soccer-specific movements. Am. J. Sports Med. 2004, 32, 140-145. [CrossRef]

11. Park, C.; Lee, S.; Kim, S.; Hwangbo, G. The effects of the application of low-dye taping on paretic side plantar pressure among patients with plantar fasciitis. J. Phys. Ther. Sci. 2015, 27, 3555-3557. [CrossRef] [PubMed]

12. Lange, B.; Chipchase, L.; Evans, A. The effect of low-Dye taping on plantar pressures, during gait, in subjects with navicular drop exceeding $10 \mathrm{~mm}$. J. Orthop. Sports Phys. Ther. 2004, 34, 201-209. [CrossRef] [PubMed]

13. Franettovich, M.M.; Murley, G.S.; David, B.S.; Bird, A.R. A comparison of augmented low-Dye taping and ankle bracing on lower limb muscle activity during walking in adults with flat-arched foot posture. J. Sci. Med. Sport 2012, 15, 8-13. [CrossRef] [PubMed]

14. Teymouri, M.; Halabchi, F.; Mirshahi, M.; Mansournia, M.A.; Mousavi Ahranjani, A.; Sadeghi, A. Comparison of plantar pressure distribution between three different shoes and three common movements in futsal. PLoS ONE 2017, 12, e0187359. [CrossRef]

15. Kawczynski, A.; Mroczek, D.; Frackiewicz, A.; Chmura, P.; Becella, L.; Samani, A.; Madeleine, P.; Chmura, J. Effects of two recovery procedures after a football game on sensory and biochemical markers. J. Sport Med. Phys. Fit 2014, 54, 394-402.

16. Vicenzino, B.; McPoil, T.; Buckland, S. Plantar foot pressures after the augmented low dye taping technique. J. Athl. Train. 2007, 42, 374-380.

17. Franettovich, M.; Chapman, A.; Blanch, P.; Vicenzino, B. A physiological and psychological basis for anti-pronation taping from a critical review of the literature. Sports Med. 2008, 38, 617-631. [CrossRef] 
18. Fallon, J.B.; Bent, L.R.; McNulty, P.A.; Macefield, V.G. Evidence for strong synaptic coupling between single tactile afferents from the sole of the foot and motoneurons supplying leg muscles. J. Neurophysiol. 2005, 94, 3795-3804. [CrossRef]

19. Madeleine, P.; Hoej, B.P.; Fernandez-de-Las-Penas, C.; Rathleff, M.S.; Kaalund, S. Pressure pain sensitivity changes after use of shock-absorbing insoles among young soccer players training on artificial turf: A randomized controlled trial. J. Orthop. Sports Phys. Ther. 2014, 44, 587-594. [CrossRef]

20. Radford, J.A.; Landorf, K.B.; Buchbinder, R.; Cook, C. Effectiveness of low-Dye taping for the short-term treatment of plantar heel pain: A randomised trial. BMC Musculoskelet Disord 2006, 7, 64. [CrossRef]

21. Osborne, H.R.; Allison, G.T. Treatment of plantar fasciitis by LowDye taping and iontophoresis: Short term results of a double blinded, randomised, placebo controlled clinical trial of dexamethasone and acetic acid. Br J Sports Med 2006, 40, 545-549, discussion 549. [CrossRef] [PubMed]

22. Sandrey, M.A.; Zebas, C.J.; Bast, J.D. Rear-foot motion in soccer players with excessive pronation under 4 experimental conditions. J. Sport Rehabil. 2001, 10, 143-154. [CrossRef]

23. Ator, R.; Gunn, K.; McPoil, T.G.; Knecht, H.G. The Effect of Adhesive Strapping on Medial Longitudinal Arch Support before and after Exercise. J. Orthop. Sports Phys. Ther. 1991, 14, 18-23. [CrossRef]

24. Kawczynski, A.; Samani, A.; Fernández-de-las-Peñas, C.; Chmura, J.; Madeleine, P. Sensory mapping of the upper trapezius muscle in relation to consecutive sessions of eccentric exercise. J. Strength Cond. Res. 2012, 26, 1577-1583. [CrossRef] [PubMed]

25. De Hoyo, M.; Alvarez-Mesa, A.; Sanudo, B.; Carrasco, L.; Dominguez, S. Immediate effect of kinesio taping on muscle response in young elite soccer players. J. Sport Rehabil. 2013, 22, 53-58. [CrossRef] [PubMed]

26. Morasiewicz, P.; Konieczny, G.; Dejnek, M.; Morasiewicz, L.; Urbanski, W.; Kulej, M.; Dragan, S.L.; Dragan, S.F.; Pawik, L. Pedobarographic analysis of body weight distribution on the lower limbs and balance after ankle arthrodesis with Ilizarov fixation and internal fixation. Biomed. Eng. Online 2018, 17, 174. [CrossRef]

27. Faul, F.; Erdfelder, E.; Buchner, A.; Lang, A.G. Statistical power analyses using G*Power 3.1: Tests for correlation and regression analyses. Behav. Res. Methods 2009, 41, 1149-1160. [CrossRef]

28. Russek, L. Factors affecting interpretation of reliability coefficients. J. Orthop. Sports Phys. Ther. 2004, 34, 341-349. [CrossRef]

29. Weir, J.P. Quantifying test-retest reliability using the intraclass correlation coefficient and the SEM. J. Strength Cond. Res. 2005, 19, 231-240.

30. Khamis, S.; Yizhar, Z. Effect of feet hyperpronation on pelvic alignment in a standing position. Gait Posture 2007, 25, 127-134. [CrossRef]

31. Chae, Y.H.; Kim, J.S.; Kang, Y.; Kim, H.Y.; Yi, T.I. Clinical and Biomechanical Effects of Low-Dye Taping and Figure-8 Modification of Low-Dye Taping in Patients With Heel Pad Atrophy. Ann. Rehabil. Med. 2018, 42, 222-228. [CrossRef] [PubMed]

32. O'Sullivan, K.; Kennedy, N.; O'Neill, E.; Ni Mhainin, U. The effect of low-dye taping on rearfoot motion and plantar pressure during the stance phase of gait. BMC Musculoskelet. Disord. 2008, 9, 111. [CrossRef] [PubMed]

33. Yoho, R.; Rivera, J.J.; Renschler, R.; Vardaxis, V.G.; Dikis, J. A biomechanical analysis of the effects of low-Dye taping on arch deformation during gait. Foot 2012, 22, 283-286. [CrossRef]

34. Russo, S.J.; Chipchase, L.S. The effect of low-Dye taping on peak plantar pressures of normal feet during gait. Aust. J. Physiother. 2001, 47, 239-244. [CrossRef]

35. Nolan, D.; Kennedy, N. Effects of low-dye taping on plantar pressure pre and post exercise: An exploratory study. BMC Musculoskelet. Disord. 2009, 10, 40. [CrossRef]

36. Verbruggen, L.A.; Thompson, M.M.; Durall, C.J. The Effectiveness of Low-Dye Taping in Reducing Pain Associated With Plantar Fasciitis. J. Sport Rehabil. 2018, 27, 94-98. [CrossRef]

37. Domínguez-Martín, M.; López-Ruiz, F.; Reyes-López, M.V.; Valenza, G.; Fernández De Las Peñas, C.; Madeleine, P. Differences in pressure pain sensitivity of elite male soccer players on artificial turf and natural grass. Sport Technol. 2013, 6, 22-28. [CrossRef]

38. Slupik, A.; Dwornik, M.; Bialoszewski, D.; Zych, E. Effect of Kinesio Taping on bioelectrical activity of vastus medialis muscle. Preliminary report. Ortop. Traumatol. Rehabil. 2007, 9, 644-651.

(C) 2020 by the authors. Licensee MDPI, Basel, Switzerland. This article is an open access article distributed under the terms and conditions of the Creative Commons Attribution (CC BY) license (http://creativecommons.org/licenses/by/4.0/). 